\title{
Quantitative evaluation of improper backfilling in vertical borehole
}

\author{
Shangyuan CHEN* and Jinfeng MAO* \\ *Institute of Military Environmental Teaching \& Research, PLA University of Science \& Technology \\ 1 Haifu Street, Qinhuai District, Nanjing 210007, China \\ E-mail: maojinfeng628@163.com
}

Received 5 January 2016

\begin{abstract}
Vertical ground heat exchanger (GHE) is widely being used to exchange heat into the ground by using the system of ground source heat pump (GSHP). The stability and thermal performance of GHE mainly relate to the grout, the advantages of GHE can be negated if the grout is not backfilled properly. In order to study the influence of grout backfilling in a vertical GHE, this study established a 2D steady-state heat conduction model, which simulated 4 cases as follows: (1) fine backfilling, (2) porous backfilling, (3) hole-wall delaminating and (4) pipe-wall delaminating. The thermal resistances inside borehole in 4 cases were estimated by using numerical and analytical methods. It has been observed that improper backfilling generates heat barriers, prolongs the time required for heat transfer and reduces heat exchange capacity. The pipe-wall delaminating greatly increases the thermal resistance and brings the worst impact to a GHE.
\end{abstract}

Key words : Vertical ground heat exchangers, Improper backfilling, Thermal resistance, Heat transfer

\section{Introduction}

As a new technique of renewable energy, GSHP system is widely being used in many countries of the world, e.g., Netherlands, Austria, Germany and China. It uses the superficial earth energy as a heat source or heat sink, extracts heat from ground in heating season and releases heat to ground in cooling season, and therefore, achieves heat exchange between the structure and the underground based on a closed pure water or antifreeze fluid system. It offers higher efficiency in terms of energy saving for air conditioning system rather than conventional system, because the underground provides a lower temperature during summer and a higher temperature during winter; both of them fluctuate lightly compared to ambient air temperature. It discharges less pollution owing to its utility of unexhausted clean energy (Sanner et al., 2003; Qing et al., 2009; Sarbu et al., 2014).

The vertical GSHP has many advantages as follows: area requirement is small, heat exchange is steady, and energy efficiency is high. A detailed review of vertical GSHP systems, included models and applications, was published by $\mathrm{H}$. Yang et al.(2010), a number of solutions for heat transfer outside and inside of the borehole has been introduced, such as infinite line source model (ILS) (Ingersoll and Plass, 1948), Ingersoll et al.(1954)'s infinite cy lindrical source model (ICS) and Zeng et al.(2002)'s finite line source solution (FLS), all of them are based on analytical methods to solve the heat transfer from the borehole wall to surroundings. In ILS and ICS, the borehole is respectively assumed as an infinite line-source and as a cylinder-source, surrounded by homogeneous ground with uniform initial temperature, and the heat transfer in axial direction is neglected. Whereas, FLS took the influence of borehole length into consideration, which is much more adequate for the case of GHE.

It is general to model the heat transfer as a steady-state process inside the borehole, the effective thermal resistance $\left(\mathrm{R}_{b}\right)$ between the walls of pipe and borehole is crucial in designing and simulating vertical GHE. With the arrangement of branches of buried pipe and the properties of grouting materials, it is difficult to obtain a closed analytical solution for $\mathrm{R}_{b}$. Shonder and Beck (1999) presented an approximate model that considered the U-tube as a single "equivalent" pipe and neglected the axial heat flow, the formulation of $\mathrm{R}_{b}$ with simplified one-dimension was given by:

$$
R_{b}=\frac{1}{2 \pi k_{b}} \ln \left(\frac{r_{b w}}{r_{p} \sqrt{n}}\right)
$$

Where $n$ is the number of pipes inside the borehole (e.g., $n=2$ for the case of a single U-tube; $n=4$ for the case of a double U-tube), $k_{b}$ is the thermal conductivity of the grout material, $r_{b w}$ is the radius of borehole, and $r_{p}$ is the borehole of pipe. The model has oversimplified the arrangement of branches in the sense that its result does not depend on distance between two pipes. 
$\mathrm{Gu}$ and O'Neal (1998) considered the shank spacing as an influencing factor, they used the conformal mapping technique and the principle of superposition of multiple heat source, and then obtained an expression for heat transfer in a borehole as follows:

$$
R_{b}=\frac{1}{2 \pi k_{b}} \ln \left(\frac{r_{b w}}{r_{p}} \sqrt{\frac{2 r_{p}}{s}}\right)
$$

Where $s$ is the shank spacing. Although Eq. (2) considers the actual position of pipes, yet it overestimated the thermal resistance owing to the effect of thermal short-circuiting between the pipes of inlet and outlet has been ignored.

On the basis of field test for a GHE, Remund (1999) derived empirical shape coefficients $\left(\beta_{o}\right.$ and $\left.\beta_{i}\right)$, which indicate three different configurations (Fig. 1) to determine $R_{b}$ (Eq. (3)). The two pipes are located at the center of the borehole in configuration I and spaced from each other in configuration II, whereas the pipes touch the borehole wall in configuration III. The values of coefficients are given in Table 1.

$$
R_{b}=\frac{1}{\beta_{o}\left({ }^{r_{b w} / r_{p}}\right)^{\beta_{i} k_{b}}}
$$
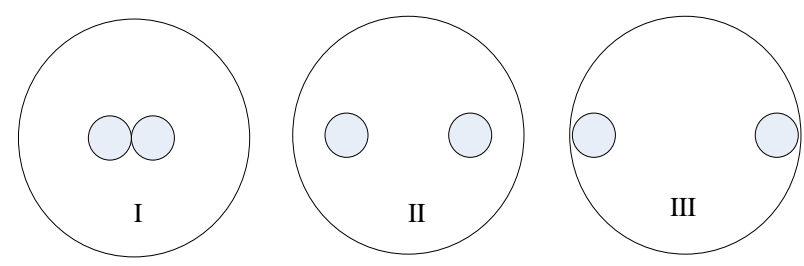

Fig. 1 Inner circles correspond to the two pipes of the U-tube installed in a borehole

Table 1 The value for $\beta_{0}, \beta_{1}$ with different configurations

\begin{tabular}{c|c|c}
\hline \hline Configuration & $\beta_{0}$ & $\beta_{1}$ \\
\hline I & 20.10 & -0.9447 \\
II & 17.44 & -0.6052 \\
III & 21.91 & -0.3796 \\
\hline
\end{tabular}

The empirical equation (Eq. (4)) presented by Sharqawy et al. (2009) on the basis of 2D steady-state model of GHE, it has been obtained in a dimensionless form. On the basis of comparison with the approximate analytical solutions, it is conclude that the analytical solutions do not accurately represent the bo rehole's thermal resistance.

$$
R_{b}=\frac{1}{2 \pi k_{b}}\left[-1.49\left(\frac{s}{2 r_{b w}}\right)+0.656 \ln \left(\frac{r_{b w}}{r_{p}}\right)+0.436\right]
$$

Usually, the U-tube with diameter in a range between of $12 \sim 5 \mathrm{~mm}$ is installed in a borehole of diameter approximately $100 \sim 150 \mathrm{~mm}$, the gap between the pipes and the borehole wall is backfilled with a mixture of grout and sand to ensure the efficiency of heat transfer. The borehole can play its role as a heat exchange medium especially under the condition of ideal backfilling, whereas it is very difficult in field situations due to manual backfilling and due to neglecting the geological conditions.

Often borehole is backfilled with only sand, which loses the grout and damages the cohesion inside the borehole, leads to an ineffective GHE, as it has been shown in Fig. 2. Philippacopoulos and Berndt (2001) has calculated the thermal resistance generated by gaps with equivalent diameter and found that gaps in a borehole can hinder the heat expansion and reduce the ground heat exchange. Meng and Guo (2010) has evaluated the influence of the grout materials on GSHP, he showed the results that improper backfilling will not only low the performance of heat pu mp, but also lead to unnecessary consequences such as sedimentation and cross-contamination of underground water. 


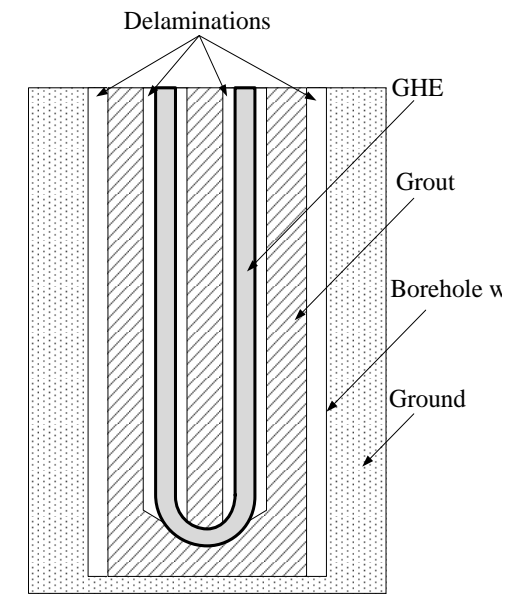

Fig. 2 Schematic diagram of improper backfilling

\section{Nomenclature}

\section{$R$}

\section{$r$}

\section{$k$}

$\mathrm{n}$

$s$

$T$

$\beta_{0}, \beta_{1}$

$q$

$\varphi$

$m$

F

V

H

Subscsripts

\section{$b$}

bw

$g$

$p$

$p 1$

p2

$\infty$

$1 b$

$2 b$

$p b$

12

eff

air

Superscripts

A, B, C, D thermal resistance $(\mathrm{m} \mathrm{K} / \mathrm{W})$

$$
\text { radius (m) }
$$

thermal conductivity (W/m K)

number of pipes in the borehole

shank spacing $(\mathrm{m})$

temperature $(\mathrm{K})$

shape coefficients

heat transfer rate per unit length $(\mathrm{W} / \mathrm{m})$

porosity of backfill

number of nodes on borehole wall

backfilling area $\left(\mathrm{m}^{2}\right)$

filling grout volume $\left(\mathrm{m}^{3}\right)$

drilling depth (m)

$$
\text { backfilling material }
$$

borehole wall

ground

pipe

inlet pipe

outlet pipe

undisturbed boundary

inlet pipe-to-borehole

outlet pipe-to-borehole

pipe-to-borehole

inlet pipe-to-outlet pipe

effective

gap

case A, B, C and D

\section{Methods}

\subsection{Model description}

The present analysis focuses on the thermal resistance in a borehole subject to improper backfilling. A 2D steady-state heat conduction model has been established in accordance with a vertical U-tube structure (Fig. 3). All previous research (Hellström, 1991; Zeng et al., 2003; Loveridge and Powrie, 2014) show that the most models had the 
following as sumptions: the wall of borehole confirms to either the first or the third kind of boundary condition, as the temperature as well as the heat exchange capacity of the borehole's wall is constant. It is pertinent to note that the value is uneven along the circumferential direction due to the temperature difference of in let and outlet pipes (Lamarche and Kajl, 2010). The assumptions applied in the heat transfer of GHE simulation are the followings as:

- Physical properties are homogenous, isotropic, and independent of temperature.

- The far boundary temperature is constant of $290.55 \mathrm{~K}$ which is the average underground temperature.

- The borehole's wall is considered as a continuum interface.

- $\quad$ The temperatures of pipes are constant of $303 \mathrm{~K}$ and $301 \mathrm{~K}$, respectively.

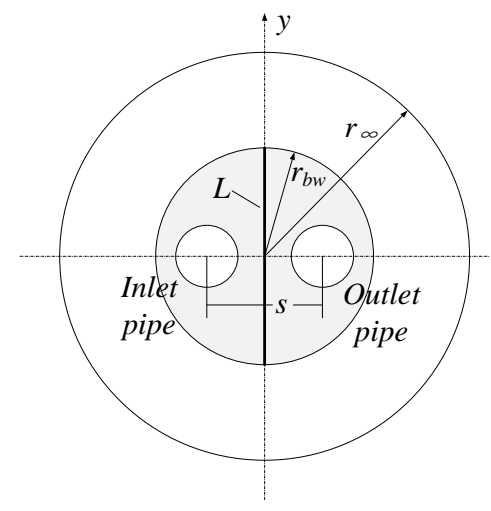

Fig. 3 Schematic diagram of U-tube heat exchanger

The governing equations of energy inside and outside the borehole region can be written as follows:

$\frac{\partial^{2} T_{b}}{\partial x^{2}}+\frac{\partial^{2} T_{b}}{\partial y^{2}}=0, \sqrt{x^{2}+y^{2}} \leq r_{b w}$

$\frac{\partial^{2} T_{\mathrm{g}}}{\partial x^{2}}+\frac{\partial^{2} T_{\mathrm{g}}}{\partial y^{2}}=0, r_{b w}<\sqrt{x^{2}+y^{2}}$

The internal and external boundaries are expressed as follows:

$T_{p 1}=303.00 \mathrm{~K}, T_{p 2}=301.00 \mathrm{~K}$

$\left.T_{\mathrm{g}}\right|_{r=r_{\infty}}=290.55 \mathrm{~K}$

The borehole's wall is regarded as an interface between grout and ground, and it can be written as follows:

$$
\begin{aligned}
& \left.k_{b} \frac{\partial T_{b}}{\partial r}\right|_{r=r_{b w}}=\left.k_{\mathrm{g}} \frac{\partial T_{\mathrm{g}}}{\partial r}\right|_{r=r_{b w}} \\
& \left.T_{b}\right|_{r=r_{b w}}=\left.T_{\mathrm{g}}\right|_{r=r_{b w}}
\end{aligned}
$$

Where $T_{b}$ and $T_{\mathrm{g}}$ are the temperatures inside and outside of borehole respectively; $r_{\infty}$ is the radius of far-boundary; $T_{\mathrm{p} 1}, T_{\mathrm{p} 1}$ and $T_{\infty}$ are the mean temperatures respectively of inlet pipe, outlet pipe and far-boundary.

The arrangement of thermal resistances inside a borehole has been shown in Fig. 4. $\mathrm{q}_{p 1}$ and $\mathrm{q}_{p 2}$ are the heat flows respectively from inlet and outlet pipe to the whole system, and $\mathrm{q}_{b w}$ is the heat flow from borehole wall to the ground, these flows can be obtained numerically by integrating Fourier's law over the pipe and borehole surfaces . $\mathrm{q}_{12}$ is the short-circuit heat flow between two pipes, it can be obtained by assessing the heat flow through line L in Fig.3 (Li et al., 2014). $\mathrm{q}_{1 b}$ and $\mathrm{q}_{2 b}$ are the heat flows respectively from inlet and outlet pipes towards the borehole's wall. The relationship between the heat flows can be written as follows (Zeng et al., 2003):

$$
\begin{aligned}
& q_{b w}=q_{p 1}+q_{p 2} \\
& q_{1 b}=q_{p 1}-q_{12} \\
& q_{2 b}=q_{p 2}+q_{12}
\end{aligned}
$$

The thermal resistances can be calculated by Eqs. (14), (15) and (16).

$$
R_{p b}=\frac{1}{2}\left(\left|\frac{T_{p 1}-T_{b w}}{q_{1 \mathrm{~b}}}\right|+\left|\frac{T_{p 2}-T_{b w}}{q_{2 \mathrm{~b}}}\right|\right)
$$




$$
\begin{aligned}
& R_{12}=\frac{T_{p 1}-T_{p 2}}{q_{12}} \\
& R_{b}=\frac{\frac{T_{p 1}+T_{p 2}}{2}-T_{b w}}{q_{\mathrm{bw}}}
\end{aligned}
$$

Where $R_{p b}$ is the thermal resistance between the pipes and borehole's wall; $R_{12}$ is the thermal resistance between the inlet and outlet pipes.

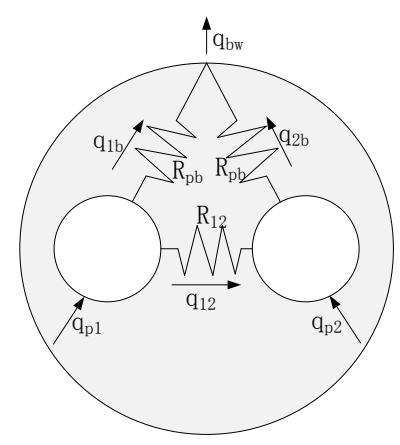

\subsection{Background information for model simulation}

Fig. 4 Diagram of heat resistances inside borehole

4 cases of backfill were simulated numerically by using finite-volume method and computational fluid dynamics (CFD) as follows:

A. Fine backfilling, medium bond closely;

B. Porous backfilling, grout media is porous and pores distribute uniformly;

C. Hole-wall delaminating, produces gap near the borehole wall;

D. Pipe-wall delaminating, produces gap near the pipes.

The gaps of case $\mathrm{C}$ and $\mathrm{D}$ are regarded as homogeneous rings. The meshes have been checked for cell skewness and aspect ratio in accordance with normal CFD standards, as shown in Fig. 5, where $\varphi$ is the porosity of backfill, $r_{\mathrm{bw}}^{\prime}$ is the radius of borehole that excludes the gap, and $r_{p}^{\prime}$ is the radius of pipe that includes the gap. The grout domain is meshed using tri-pave grid, whereas the soil and gaps is meshed using quad-map grid. Convergence is deemed to be reached if the residuals are smaller than $5 \times 10^{-5}$.

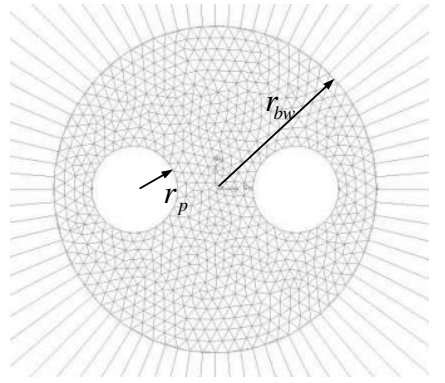

Case A (Fine backfilling)

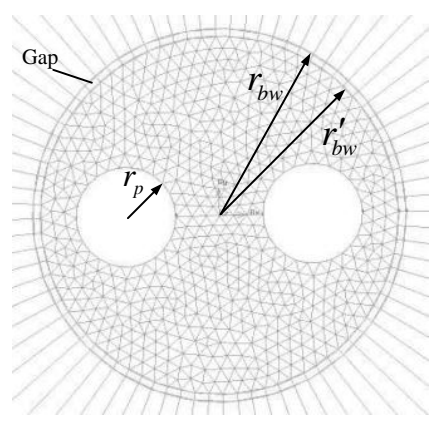

Case C (Hole-wall delaminating)

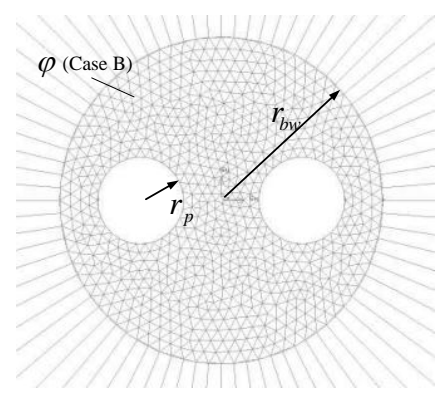

Case B (Porous backfilling)

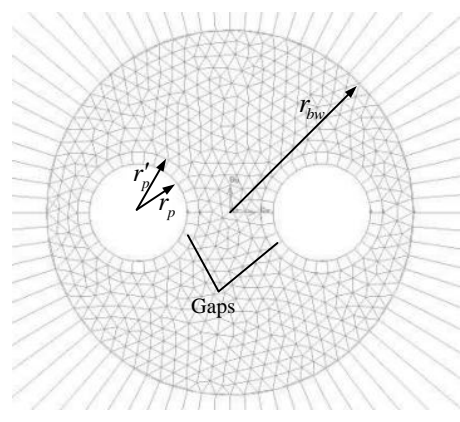

Case D (Pipe-wall delaminating)

Fig. 5 Grids of 4 cases 
The temperature value and heat flow are calculated by the methods of point average and surface integral weighted average as follows:

$$
\begin{aligned}
& T_{b w}=\frac{1}{m} \sum_{i=1}^{m} T_{i} \\
& q_{\mathrm{bw}}=\frac{1}{A} \int q \mathrm{~d} A
\end{aligned}
$$

Where $m$ is the number of nodes on the borehole's wall, $T_{i}$ is the temperature value of node. $q$ is the heat flow through surface A.

\section{Model validation}

In all cases, the undisturbed boundary is set as $r_{\infty}=5 \mathrm{~m}$, the borehole radius is $r_{b w}=0.06 \mathrm{~m}$, and pipe radius is $r_{p}=0.016 \mathrm{~m}$, the physical parameters are listed in Table 2 . The results of steady-state heat conduction in the borehole are obtained in Table 3, it is found that $R_{b}$ increases either by increasing the values of $\varphi$ and $r_{p}^{\prime}$, or by decreasing $r_{b w}^{\prime}$.

Table 2 Calculating parameters of GHE for simulation

\begin{tabular}{c|c}
\hline \hline Parameter & Value \\
\hline ground density $\left(\mathrm{kg} / \mathrm{m}^{3}\right)$ & 1350 \\
ground thermal conductivity $(\mathrm{W} / \mathrm{m} \mathrm{K})$ & 1.7 \\
ground heat capacity $(\mathrm{kJ} / \mathrm{kg} \mathrm{K})$ & 2.2 \\
grout density $\left(\mathrm{kg} / \mathrm{m}^{3}\right)$ & 2060 \\
grout thermal conductivity $(\mathrm{W} / \mathrm{m} \mathrm{K})$ & 2.4 \\
grout heat capacity $(\mathrm{kJ} / \mathrm{kg} \mathrm{K})$ & 0.65 \\
air thermal conductivity $(\mathrm{W} / \mathrm{m} \mathrm{K})$ & 0.0242 \\
\hline
\end{tabular}

\begin{tabular}{|c|c|c|c|c|}
\hline Parameters & & $q_{b w}(\mathrm{~W} / \mathrm{m} \mathrm{K})$ & $T_{b w}(\mathrm{~K})$ & $R_{e f f}(\mathrm{~m} \mathrm{~K} / \mathrm{W})$ \\
\hline \multirow{9}{*}{$\varphi$} & 0 & 19.55 & 301.02 & 0.05 \\
\hline & 0.1 & 19.47 & 300.98 & 0.052 \\
\hline & 0.2 & 19.28 & 300.87 & 0.059 \\
\hline & 0.3 & 19.03 & 300.74 & 0.066 \\
\hline & 0.4 & 18.72 & 300.57 & 0.076 \\
\hline & 0.5 & 18.31 & 300.345 & 0.09 \\
\hline & 0.6 & 17.65 & 300.02 & 0.112 \\
\hline & 0.7 & 16.82 & 299.55 & 0.146 \\
\hline & 0.8 & 15.37 & 298.78 & 0.209 \\
\hline \multirow{5}{*}{$r_{b w}^{\prime} \quad(\mathrm{m})$} & 0.0575 & 15.36 & 295.92 & 0.396 \\
\hline & 0.055 & 14.07 & 293.34 & 0.615 \\
\hline & 0.0525 & 10.19 & 292.61 & 0.921 \\
\hline & 0.05 & 7.75 & 292.22 & 1.262 \\
\hline & 0.0475 & 6.28 & 291.95 & 1.6 \\
\hline \multirow{6}{*}{$r_{p}^{\prime}(\mathrm{m})$} & 0.018 & 11.72 & 296.84 & 0.44 \\
\hline & 0.02 & 8.58 & 295.09 & 0.805 \\
\hline & 0.022 & 6.76 & 294.18 & 1.157 \\
\hline & 0.024 & 5.87 & 293.64 & 1.424 \\
\hline & 0.026 & 5.12 & 293.24 & 1.711 \\
\hline & 0.028 & 4.55 & 292.94 & 1.991 \\
\hline
\end{tabular}

Table 3 Results in accordance with different $\varphi, r_{p}^{\prime}$, and $r_{b w}^{\prime}$. 
Take the effect of improper backfilling into consideration. Case B is equivalent to change the grout conductivity from $k_{b}$ to effective conductivity $k_{\text {eff }}$ (Eq. (19)).

$k_{\text {eff }}=\varphi k_{\text {air }}+(1-\varphi) k_{b}$

In case $\mathrm{C}$, the thermal resistance of gap for conductive heat transfer can be calculated in one dimension for an annular space as follow:

$$
R_{\text {air }}^{\mathrm{C}}=\frac{1}{2 \pi k_{\text {air }}} \ln \frac{r_{b w}}{r_{b w}^{\prime}}
$$

In case $\mathrm{D}$, the two annuli in parallel position, the thermal resistance of gap can be calculated as:

$$
R_{\text {air }}^{\mathrm{D}}=\frac{1}{4 \pi k_{\text {air }}} \ln \frac{r_{p}}{r_{p}^{\prime}}
$$

The effective thermal resistances $R_{e f f}$ in case $\mathrm{B}, \mathrm{C}$ and $\mathrm{D}$ can be modified by combining the equations of $R_{b}$ as presented by Shonder and Beck (1999), Gu and O’Neal (1998), Remund (1999) and Sharqawy et al. (2009).

$$
\begin{aligned}
& R_{e f f}^{\mathrm{B}}=\frac{k_{b}}{k_{e f f}} R_{b} \\
& R_{e f f}^{\mathrm{C}}=R_{b}+\frac{k_{b}-k_{\text {air }}}{2 \pi k_{\text {air }} k_{b}} \ln \frac{r_{b w}}{r_{b w}} \\
& R_{e f f}^{\mathrm{D}}=R_{b}+\frac{k_{b}-k_{\text {air }}}{4 \pi k_{\text {air }} k_{b}} \ln \frac{r_{p}}{r_{p}^{\prime}}
\end{aligned}
$$

The $R_{\text {eff }}$ is plotted in Fig. 6 8, as calculated from Eqs. (22), (23), and (24). By comparing the numerical results with analytical solutions, it is found that the curves are almost similar, which validate the feasibility and effectiveness of models.

When the porosity is varied between 0 and 0.8 in Fig. 6 , the $R_{\text {eff }}$ may increase to a greater extent. By comparing the results of case B with models, the numerical results are approximately 6 22\% higher than Remund (1999) and 15 26\% lower than Sharqawy et al. (2009).

As we have discussed above, the results achieved from Shonder and Beck (1999) as well as from Gu and O’Neal (1998) are higher than that of usual practice. Remund (1999)'s solution only adopt experimental method after studing few cases. Sharqawy et al. (2009)'s empirical equation is based on the assumption that temperature of borehole's wall is constant, which brings error into the result. The curves in Fig. 7 descend with the same slope, the $R_{\text {eff }}$ of case C decreases from 1.58 to 0.34 with $r_{b w}^{\prime}$ that varies from 0.0475 to 0.0575 . As shown in Fig. $8, R_{e f f}$ of case D gradually increases with $r_{p}^{\prime}$ that approaches to 0.028 , it means that the value of $R_{e f f}$ is proportional to the size of $g a p$.

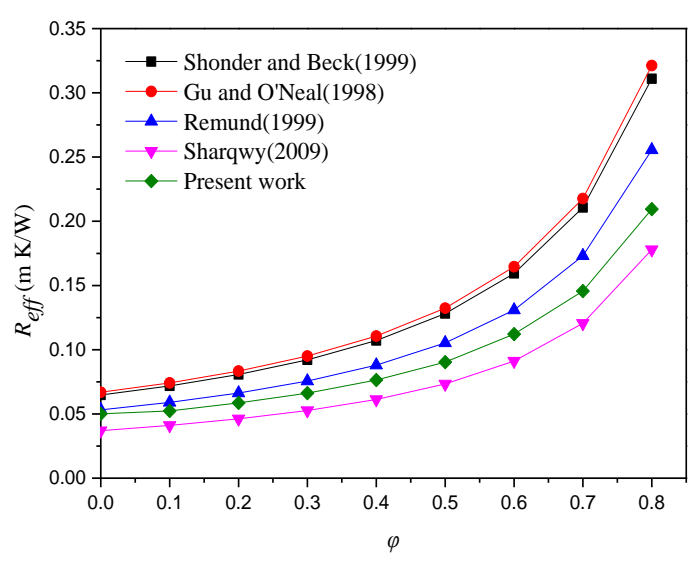

Fig. 6 Variation of $R_{\text {eff }}$ with porosity 


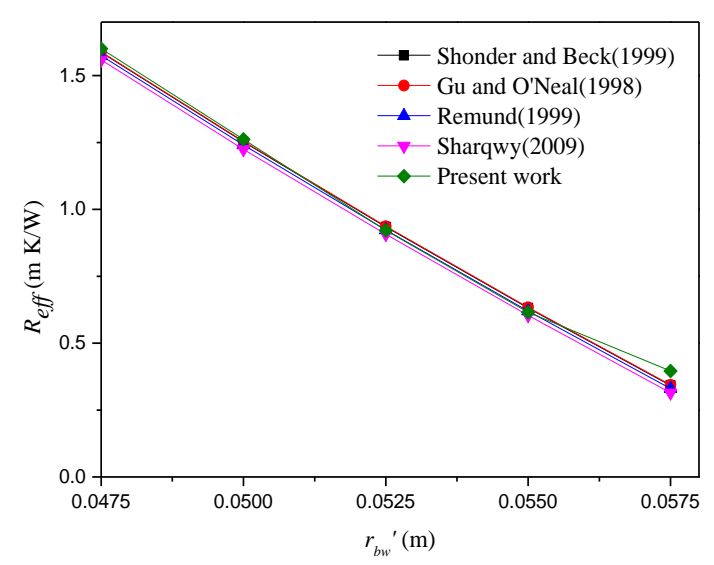

Fig. 7 Variation of $R_{\text {eff }}$ with $r_{b w}^{\prime}$

\section{Results and discussion}

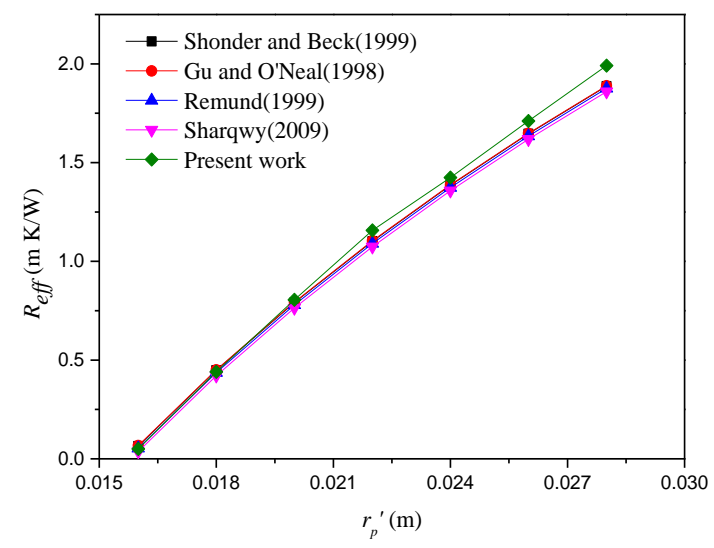

Fig. 8 Variation of $R_{\text {eff }}$ with $r_{p}^{\prime}$

4 cases are compared to assess the damage brought by improper backfilling. By considering the equal amount of grout in case $\mathrm{B}, \mathrm{C}$ and $\mathrm{D}\left(F^{\mathrm{B}}=F^{\mathrm{C}}=F^{\mathrm{D}}\right)$, the backfilled area $F$ can be calculated by Eqs. (25), (26), (27) and (28). We selected $\varphi=0.093, r_{p}^{\prime}=0.02 \mathrm{~m}$, and $r_{b w}^{\prime}=0.0575 \mathrm{~m}$.

$$
\begin{aligned}
& F^{\mathrm{A}}=\pi r_{b w}^{2}-2 \pi r_{p}^{2} \\
& F^{\mathrm{B}}=(1-\varphi) F^{\mathrm{A}} \\
& F^{\mathrm{C}}=\pi r_{b w}^{\prime 2}-2 \pi r_{p}^{2} \\
& F^{\mathrm{D}}=\pi r_{b w}^{2}-2 \pi r_{p}^{\prime 2}
\end{aligned}
$$

\subsection{Comparison of temperature fields}

Refer to Fig. 9 to compare the temperature contours of 4 cases. Temperature inside borehole is raised by heat transfer, and the rising rate is decreased as its range expanded. There is a phenomenon of short-circuit appeared in the middle of two pipes. The $T_{b w}$ of case A is $301.02 \mathrm{~K}$ calculated by Eq. (17). Temperature contours of case B are similar to case A, whereas the radius of thermal diffusion diminishes and $T_{b w}$ is $300.98 \mathrm{~K}$. In case $\mathrm{C}$, the $R_{p b}$ increases due to hole-wall delaminating, where heat accumulates in the borehole and diffuses difficultly. In case $\mathrm{D}$, the $R_{p b}$ and $R_{12}$ increase greatly, the ground temperature is almost unchanged.

Fig. 10 shows the temperature of scatters, the intervals $(-0.06,0.06),(-0.046,-0.014)$ and $(0.014,0.046)$ represent the region of borehole, in let pipe and outlet pipe respectively. The temperature distributions of case A, B and C are similar with each other in the borehole. As heat is accumulated in the borehole, temperature of case $\mathrm{C}$ is a little higher than that of case A and B, and the temperature of case D is lowest obviously. We can conclude that the improper backfilling would weaken the process of heat transfer. 


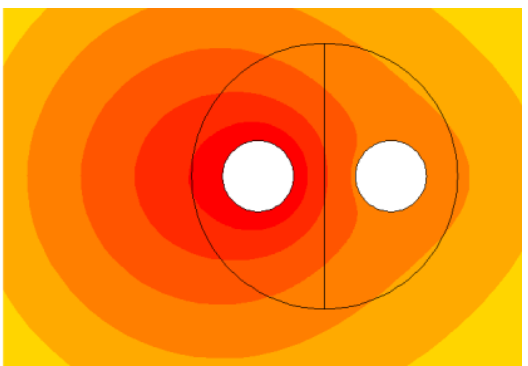

Case A (Fine backfilling)

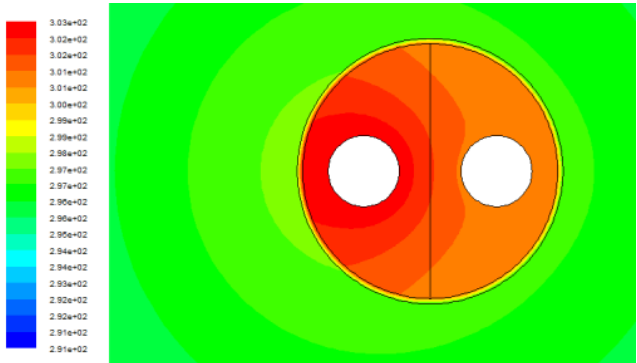

Case C (Hole-wall delaminating)



Case B (Porous backfilling)

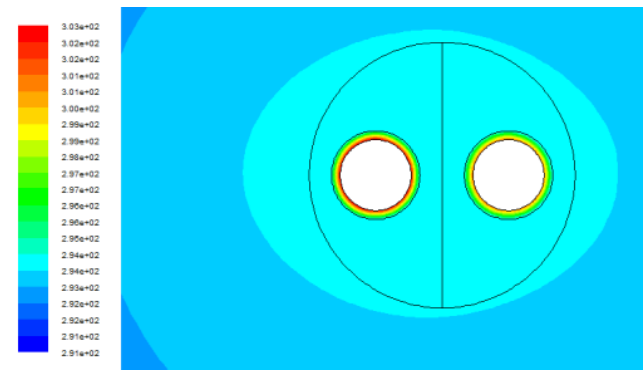

Case D (Pipe-wall delaminating)

Fig. 9 The temperature distribution around borehole in steady-state

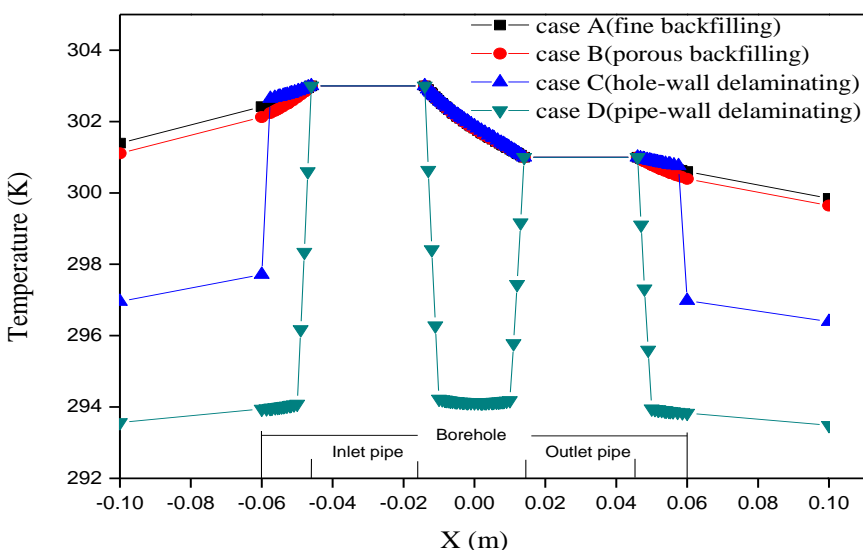

Fig. 10 Temperature distribution of scatters on X-axis

The results are calculated by Eqs.(14) (16), as listed in Table 4. Compare with case A, the $R_{p b}$ of case C increases to 1.439. The $R_{p b}$ and $R_{12}$ of case D are also increase to 1.625 and 5.263 respectively.

Table 4 The results of numerical calculation

\begin{tabular}{c|c|c|c|c|c|c}
\hline \hline Case & $\begin{array}{c}T_{b w} \\
(\mathrm{~K})\end{array}$ & $\begin{array}{c}q_{p 1} \\
(\mathrm{~W} / \mathrm{m})\end{array}$ & $\begin{array}{c}q_{12} \\
(\mathrm{~W} / \mathrm{m})\end{array}$ & $\begin{array}{c}q_{p 2} \\
(\mathrm{~W} / \mathrm{m})\end{array}$ & $\begin{array}{c}R_{p b} \\
(\mathrm{~m} \mathrm{~K} / \mathrm{W})\end{array}$ & $\begin{array}{c}R_{12} \\
(\mathrm{~m} \mathrm{~K} / \mathrm{W})\end{array}$ \\
\hline A & 301.02 & 30.99 & 20.09 & -11.44 & 0.09198 & 0.09955 \\
B & 300.98 & 29.15 & 18.20 & -9.68 & 0.09341 & 0.10989 \\
C & 295.92 & 32.62 & 19.43 & -17.26 & 1.43889 & 0.10293 \\
D & 295.09 & 4.47 & 0.38 & 4.11 & 1.62512 & 5.26316 \\
\hline
\end{tabular}

\subsection{Comparison of heat transfer capacity}




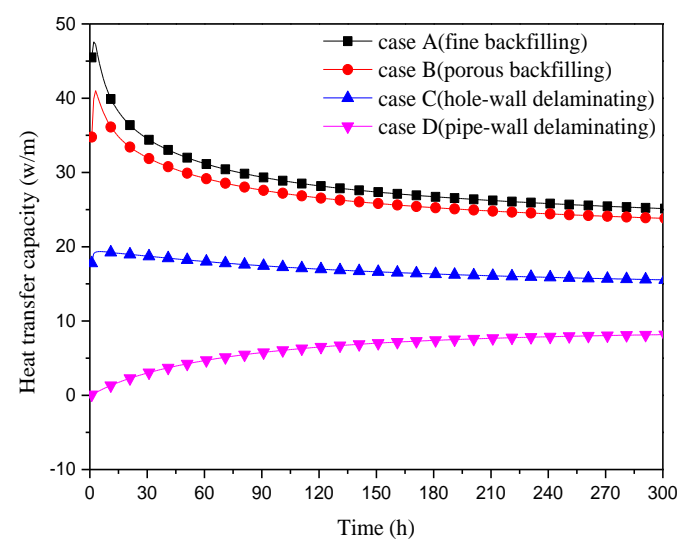

Fig. 11 The variation of heat transfer capacity with time

The process of heat transfer in soil is transient, Fig. 11 shows the capacity of heat transfer that is exchanged in different degrees when the backfill is either loose or delaminated. In case A, $q_{b w}$ is decreased from $47.6 \mathrm{~W} / \mathrm{m}$ to $25.1 \mathrm{~W} / \mathrm{m}$ in $0 \sim 300 \mathrm{~h}$, of which the decline is faster at the primary stage and slower at the subsequent stage. Case B is slightly below case $\mathrm{A}$, whereas the two cases have similar variation trend. The changes of case $\mathrm{C}$ are not pronounced and the curve is declined as a whole. In case D, $q_{b w}$ is inclined hourly and stabilized at $7.9 \mathrm{~W} / \mathrm{m}$.

The comparison of average heat flow shows that, the $q_{b w}$ is $28.9 \mathrm{~W} / \mathrm{m}$ in case of fine backfilling and it declines by $6.3 \%, 41.5 \%$ and $78.4 \%$ respectively in case of porous backfilling, hole-wall delaminating and pipe-wall delaminating, whereas the case D brings the worst impact to GHE. As there is an insulating layer formed in such a region which impedes heat expansion and the impediment can be more striking when the insulating layer is closer to the heat source. Case $\mathrm{C}$ has its grout delaminated on the wall of borehole, which is the most distant to buried pipes. Case D's insulating layer is located at the wall of buried pipes and limited heat expansion dramatically. Whereas case B is just like decentralizing a same-size insulating layer in the whole borehole, which has relatively a slight heat-insulating effect and has declined in heat exchange.

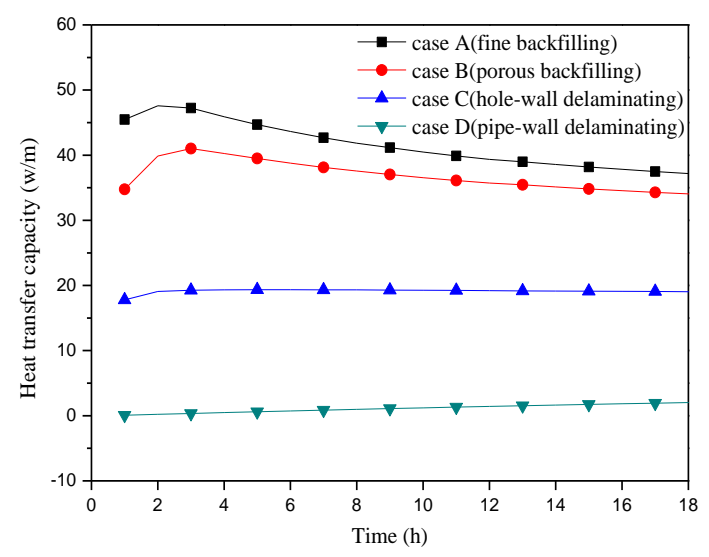

Fig. 12 The variation of heat transfer capacity in early time

The heat exchange curves of case A, B, C are inclined in early period (Fig. 12), this is due to the system's original temperature of $290.55 \mathrm{~K}$ and the exothermic effect of buried pipes. With the passage of time, heat exchange declines after it reached its maximum. The case A, B, C made their maximum at $2 \mathrm{~h}, 3 \mathrm{~h}$ and $7 \mathrm{~h}$, whereas case D did it for a longer time. Thereafter, it can be observed that the improper backfilling will prolong the time required to transmit the heat towards the wall of borehole and hence it reduces the efficiency of buried pipe.

\section{Approaches planned to adopt}

In civil works, the ingredients of grout shall be selected in accordance with the geological environment, while considering its shrinkage, its bond quality and its thermal properties. Pronouncedly put forward by Technical Code for Ground-source Heat Pump System: "During the process of backfilling, the continuity should be ensured and the filling 
pipe should be extracted out gradually corresponding to a mechanical filling. The grout should be affused from top to bottom to seal the holes to ensure that the filling of borehole is closely knitted and has no cavities. Or the heat exchange shall be reduced and the project quality badly impacted" (MOHURD, 2010). Control of the grout material usage is also necessary. Under the ideal condition, the borehole backfill is compacted with a capacity equal to the volume of filled grout $(V)$. The volume of filled grout used can be estimated by Eq. (29).

$$
V=\left(\pi r_{b w}^{2}-n \pi r_{p}^{2}\right) H
$$

Where $H$ means the drilling depth.

The effect of backfilling should be examined when the hole is sealed. In this regard, the temperature sensors can be embedded in the borehole and the recorded values in borehole should keep a linear variation without sharp step change.

\section{Conclusion}

In this article, a 2D model was developed and the following 4 cases were simulated: fine backfilling, porous backfilling, hole-wall delaminating and pipe-wall delaminating. Solutions of heat conduction were obtained by finite element to evaluate the influence of potential gaps and heat barrier. The pipe-to-borehole resistance $R_{p b}$ was increased by $1.347 \mathrm{~m} \mathrm{~K} / \mathrm{W}$ and the heat exchange $q_{b w}$ was decreased by $41.5 \%$ under hole-wall delaminating. When cavities emerged on the pipe wall, the thermal resistances were greatly higher than that of other cases. Therefore, $q_{b w}$ is decreased by $78.4 \%$, and the GHE is practically inactive. Hence, we can conclude that closer locality of cavities in pipes shall brought larger damage to heat exchange. Moreover, the improper backfilling can prolong the time required to transmit the heat to the hole-wall and to reduce the efficiency of buried pipes.

It is important to note that the geological conditions be considered while, selecting the backfill material, and the mechanical filling should be adopted during the process of backfilling. Meanwhile it is necessary to control the use of filling grout and to check the backfilling's effect through the temperature sensor that was embedded before the hole was sealed.

\section{Acknowledgments}

The authors acknowledge the support provided by PLA Univ. of Sci. \& Tech. for this research project.

\section{References}

Gu, Y. and O’Neal, D. L., Development of an equivalent diameter expression for vertical U-tubes used in ground-coupled heat pumps, ASHRAE Transactions, Vol.104 (1998), pp.347-355.

Hellstrom, G, Thermal analysis of duct storage systems, Department of Mathematical Physics, University of Lund, Lund, Sweden, 1991.

Ingersoll, L. R. and Plass, H. J., Theory of the ground pipe source for the heat pump, ASHRAE Transactions, Vol.54 (1948), pp. 339-348.

Ingersoll, L. R., Zobel, O. J. and Ingersoll, A. C., Heat conduction with engineering, geological, and other applications (1954), McGraw-Hill.

Lamarche, L., Kajl, S. and Beauchamp, B., A review of methods to evaluate borehole thermal resistances in geothermal heat-pump systems, Geothermics, Vol.39 (2010), pp.187-200.

Li, Y., Mao, J. F. and Geng, S. B., Evaluation of thermal short-circuiting and influence on the thermal response test for borehole heat exchanger, Geothermics, Vol.50 (2014), pp.136-147.

Loveridge, F. and Powrie, W., 2D thermal resistance of pile heat exchangers, Geothermics, Vol.50 (2014), pp.122-135.

Meng, Z. X., Yu, Y. J. and Guo, Y. M., Influence of the backfill materials on the ground-source heat pump, Building Energy Efficiency, Vol.38, No.3 (2010), pp.69-71 (in Chinese).

MOHURD (Ministry of Housing and Urban-Rural Development, PR China) Minister of Urban, Technical code for ground-source heat pump system (2010), Ministry of Housing and Urban-Rural Development (in Chinese).

Philippacopoulos, A. J. and Berndt, M. L., Influence of debonding in ground heat exchangers used with geothermal heat pumps, Geothermics, Vol.30 (2001), pp.527-545.

Qing, G., Ming, L., Ming, Y., Spitler, J. D. and Yan, Y. Y., Review of development from GSHP to UTES in China and other countries, Renewable and Sustainable Energy Reviews, Vol.13 (2009), pp.1383-1394. 
Remund, C. P., Borehole thermal resistance: laboratory and field syudies, ASHRAE Transactions, Vol.105 (1999), pp.439-445.

Sanner, B., Karytsas, C., Mendrinos, D. and Rybach, L., Current status of ground source heat pumps and underground thermal energy storage in Europe, Geothermics, Vol.32 (2003), pp.579-588.

Sarbu, I. and Sebarchievici, C., General review of ground-source heat pump systems for heating and cooling of buildings, Energy and buildings, Vol.70 (2014), pp.441-454.

Sharqawy, M. H., Mokheimer, E. M. and Badr, H. M., Effective pipe-to-borehole thermal resistance for vertical ground heat exchangers, Geothermics, Vol.38 (2009), pp.271-277.

Shonder, J. A. and Beck, J. V., Field test of a new method for determining soil formation thermal conductivity and borehole resistance, ASHRAE Transactions, Vol.106 (1999), pp.843-850.

Yang, H., Cui, P. and Fang, Z., Vertical-borehole ground-coupled heat pumps: A review of models and systems, Applied Energy, Vol.87 (2010), pp.16-27.

Zeng, H. Y., Diao, N. R. and Fang, Z. H., A finite line-source model for boreholes in geothermal heat exchangers, Heat Transfer Asian Res., Vol.31, No.7 (2002), pp.558-567.

Zeng, H. Y., Diao, N. R. and Fang, Z. H., Efficiency of vertical geothermal heat exchangers in ground source heat pump systems, Thermal Science, Vol.12, No.1 (2003), pp.77-81.

Zeng, H. Y., Diao, N. R. and Fang, Z. H., Heat transfer analysis of boreholes in vertical ground heat exchangers, International Journal of Heat and Mass Transfer, Vol.46 (2003), pp.4467-4481. 